\title{
PADRÕES DE DOMINAÇÃO EXTERNA NA AMÉRICA LATINA ${ }^{1}$
}

\author{
NORMAS DE DOMINACIÓN EXTERNA EN AMÉRICA LATINA
}

\section{EXTERNAL DOMINATION STANDARDS IN LATIN AMERICA}

Florestan Fernandes ${ }^{2}$

\begin{abstract}
Resumo: O clássico "Padrões de dominação Externa na América Latina" é o primeiro capítulo do livro Capitalismo Dependente e Classes Sociais na América Latina "que reuni três ensaios, escritos entre fins de 1969 e começos de 1970, e de abril a julho de 1971 [este primeiro capítulo] foi inicialmente apresentado como conferência pública, proferida em 10 de março de 1970 em um dos auditórios da Universidade de Toronto; posteriormente repetida em outras universidades do Canadá e dos Estados Unidos" (FERNANDES, 1975, p.7). O objetivo central do capítulo é discutir analisar as fases e formas dominação externa na América Latina considerando o imperialismo e a hegemonia dos Estados Unidos. Cabe ressaltar que o estudo deste livro, e seu texto clássico, devem está articulado com as seguintes obras: A integração do Negro na Sociedade de Classe (1964); Sociedade de classes e subdesenvolvimento (1968) e A Revolução Burguesa no Brasil. Ensaios de interpretação sociológica (1975).
\end{abstract}

Palavras-Chave: Florestan Fernandes; Capitalismo Dependente; América Latina; Imperialismo

Abstract: The classic "Patterns of External Domination in Latin America" is the first chapter of the book Dependent Capitalism and Social Classes in Latin America "which brought together three essays, written between late 1969 and early 1970, and from April to July 1971 [this first chapter] was initially presented as a public conference, given on March 10, 1970, in one of the University of Toronto auditoriums; later repeated at other universities in Canada and the United States "(FERNANDES, 1975, p.7). The central objective of the chapter is to discuss analyzing the phases and forms of external domination in Latin America considering imperialism and the USA hegemony. It is noteworthy that the study of this book, and its classic text, must be articulated with the following works: The Integration of the Black people in Class Society (1964); Class Society and Underdevelopment (1968) and The Bourgeois Revolution in Brazil. Essays of sociological interpretation (1975).

Keywords: Florestan Fernandes; Dependent Capitalism; Latin America; Imperialism.

Resumen: El clásico "Patrones de dominación externa en América Latina" es el primer capítulo del libro Capitalismo dependiente y clases sociales en América Latina", que reunió tres ensayos, escritos entre finales de 1969 y principios de 1970, y de abril a julio de 1971 [este primero capítulo] se presentó inicialmente como una conferencia pública, dada el 10 de marzo de 1970, en uno de los auditorios de la Universidad de Toronto; luego se repitió en otras universidades de Canadá y Estados Unidos "(FERNANDES, 1975, p.7). El objetivo central del capítulo es analizar el análisis de las fases y formas de dominación externa en América Latina considerando el imperialismo y la hegemonía de Estados Unidos. Es de destacar que el estudio de este libro, y su texto clásico, debe articularse con los siguientes trabajos: La integración de los negros en la sociedad de clases (1964); Sociedad de clases y subdesarrollo (1968) y La revolución burguesa en Brasil. Ensayos de interpretación sociológica (1975).

Palavras claves: Florestan Fernandes; Capitalismo Dependiente; América Latina; Imperialismo

À semelhança de outras nações das Américas, as nações latino-americanas são produtos da 'expansão da civilização ocidental' isto é, de um tipo moderno de colonialismo organizado e sistemático. Esse colonialismo teve seu início com a "Conquista" - espanhola e portuguesa - e adquiriu uma forma mais complexa após a emancipação nacional daqueles países.

A razão dessa persistência é a evolução do capitalismo e a incapacidade dos países latinoamericanos de impedir sua incorporação dependente ao espaço econômico, cultural e político das sucessivas nações capitalistas hegemônicas. Antes de mais nada, o capitalismo transformou-se, através da história, 
segundo uma velocidade demasiado acelerada para as potencialidades históricas dos países latinoamericanos. Quando uma determinada forma de organização capitalista da economia e da sociedade era absorvida, isso ocorria em consequência de uma mudança da natureza do capitalismo na Europa e nos Estados Unidos, e novos padrões de dominação externa emergiam inexoravelmente. Por outro lado, uma organização aristocrática, oligárquica ou plutocrática da sociedade sempre concentrou extremamente a riqueza, o prestígio social e o poder em alguns estratos privilegiados. Em consequência, a institucionalização política do poder era realizada com a exclusão permanente do povo e o sacrifício consciente de um estilo democrático de vida. A integração nacional, como fonte de transformações revolucionárias e de desenvolvimento econômico, sociocultural e político, tornou-se impossível. Os interesses particularistas das camadas privilegiadas, em todas as situações, podiam ser tratados facilmente como "os interesses supremos da Nação", estabelecendo uma conexão estrutural interna para as piores manipulações do exterior.

A presente discussão não pretende descrever todos os aspectos da dominação externa e como ela foi ou é mantida socialmente ${ }^{3}$. Considerada sociologicamente, a América Latina defronta-se com dois grandes problemas. O primeiro é a nova forma de imperialismo e a sua difusão sob a hegemonia de uma superpotência capitalista, os Estados Unidos. O outro consiste em como enfrentar o imperialismo, na época das grandes empresas corporativas e da dominação implacável por parte de uma nação americana, dadas as debilidades econômicas, socioculturais e políticas predominantes, mesmo nos países mais avançados da região. Ambas as questões implicam uma discussão preliminar do assunto geral, já que a docilidade dos interesses privados latino-americanos em relação ao controle externo não constitui tão-somente uma estratagema econômico. Trata-se de um componente dinâmico de uma tradição colonial de subserviência, baseada em fins econômicos, mas também na cegueira nacional, até certo ponto estimulada e controlada a partir de fora.

\section{Fases e formas da dominação externa}

O sistema básico de colonização e de dominação externas, experimentado por quase todas as nações latino-americanas durante pelo menos três séculos, foi construído de acordo com os requisitos econômicos, culturais e políticos do assim chamado "antigo sistema colonial". Em termos jurídicos, a legitimidade de dominação tinha um duplo fundamento, legal e político. Os colonizadores eram submetidos à vontade e ao poder das Coroas de Espanha e Portugal, às quais deviam, como vassalos, obediência e lealdade. Essa identidade de interesses, das Coroas e dos colonizadores, sofreu várias rupturas. Não obstante, permitiu tanto o endosso dos interesses dos colonizadores pelas Coroas como, inversamente, uma orientação de valores pela qual os colonizadores agiam em benefício dos interesses das Coroas. Em termos sociológicos, os fundamentos legais e políticos dessa dominação colonial exigiam uma ordem social em que os interesses das Coroas e dos colonizadores pudessem ser institucionalmente preservados, incrementados e reforçados, sem outras considerações. Isso foi conseguido pela transplantação dos padrões ibéricos de estrutura social, adaptados aos trabalhos forçados dos nativos ou à escravidão (de nativos, africanos ou mestiços). Assim, uma combinação de estamentos e castas produziu uma autêntica sociedade colonial na qual 
apenas os colonizadores eram capazes de participar das estruturas existentes de poder e de transmitir posição social através da linhagem "europeia". A estratificação resultante, porém, possuía grande flexibilidade, favorecendo a absorção e o controle de massas de nativos, africanos e mestiços, classificados em categorias de castas ou mantidos fora das estruturas estamentais, como estratos dependentes. Sob tais condições societárias, o tipo legal e político de dominação colonial adquiriu caráter de exploração ilimitada, em todos os níveis da existência humana e da produção, para o benefício das Coroas e dos colonizadores.

Vários fatores estruturais ou históricos explicam a crise desse tipo de dominação. Do ponto de vista sociológico, três fatores diferentes foram realmente decisivos. Primeiro, o padrão de exploração colonial, inerente ao sistema político e legal de dominação externa. A estrutura das economias da Espanha e de Portugal não era suficientemente forte para sustentar o financiamento das atividades mercantis, relacionadas com a descoberta, a exploração e o crescimento das colônias. Veneza e, subsequentemente, a Holanda (juntamente com outros países europeus) forneceram o capital, a tecnologia, o equipamento e a base comercial do mercado internacional, convertendo-se nas potências centrais, como núcleos do capitalismo mercantil. Por isso, Espanha e Portugal desempenharam papéis econômicos intermediários e o padrão de exploração colonial tomou-se rapidamente demasiado duro, para os agentes privilegiados nas colônias latino-americanas. No caso do açúcar brasileiro, por exemplo, o "produtor" colonial retinha um lucro bruto que variava de 12 a 18\%; a Coroa absorvia aproximadamente de 25 a 30\%; os mercadores holandeses recebiam o saldo e outras vantagens, economicamente mais importantes (como os lucros produzidos pelo financiamento da produção, do transporte, da Coroa etc.; ou os elevados lucros proporcionados pela refinação do produto e por sua comercialização dos mercados europeus). Os movimentos de emancipação iniciaram-se como uma oposição radical a esse padrão complexo de exploração. Eles eram dirigidos contra as Coroas, porque somente através da independência os agentes privilegiados da economia colonial poderiam atingir os requisitos legais e políticos de sua autonomia econômica (mantidas as demais condições do sistema de produção colonial). O segundo fator, que teve uma influência decisiva na crise do antigo sistema colonial, foi a luta pelo controle econômico das colônias latinoamericanas na Europa, especialmente entre a Holanda, a França e a Inglaterra. As mudanças nas estruturas políticas, econômicas e culturais da Europa, ao término do século XVIII e no início do século XIX, contribuíram para a rápida desagregação das potências centrais e intermediárias, que detinham o controle externo do antigo sistema colonial. E, finalmente, seria necessário considerar alguns setores da população das colônias, vitimados pela rigidez da ordem social e interessados na destruição do antigo sistema colonial. Esses setores, muito heterogêneos (e, em muitos casos, predominantemente de descendência mista), incluíam habitantes das cidades e vilas, mais ou menos identificados com a nativização do poder, especialmente aos níveis econômico e político. A massa que deu, em todos os países, apoio fanático aos movimentos de emancipação nacional foi recrutada entre esses setores.

O segundo tipo de dominação externa surgiu como produto da desagregação do antigo sistema colonial. As nações europeias, que conquistaram o controle dos negócios de exportação e de importação na América Latina (a Inglaterra em particular), estavam inicialmente mais interessadas no comercio que na produção local. Durante quase quatro ou cinco décadas - do fim do século XVIII até as primeiras três ou 
quatro do século XIX - esses países ocuparam o vácuo econômico deixado pela desagregação do antigo sistema colonial, ao Invés de exercerem o papel de um "poder imperial". A situação especial da América Latina explica a direção desse processo. A produção com vistas à exportação imediata já estava organizada, numa base bastante compensadora em termos de custos. Por outro lado, a ausência de produtos de alto valor econômico e a existência de um mercado consumidor relativamente amplo tornou mais atraente o controle de posições estratégicas nas esferas comerciais e financeiras. A Inglaterra, por exemplo, iniciou uma política comercial que propiciou rápido impulso à emergência dos mercados capitalistas modernos nos centros urbanos das ex-colônias.

Durante este curto período, em que os países dominantes possuíam apenas o controle de mercado dos processos econômicos, seria possível falar-se, stricto sensu, de neocolonialismo. A dominação externa tornou-se largamente indireta. A expansão das agências comerciais e bancárias na região envolvia um pequeno número de pessoal qualificado, a difusão em escala reduzida de novas instituições econômicas e de novas técnicas sociais, e várias modalidades de associação com agentes e interesses locais e nacionais. A monopolização dos mercados latino-americanos foi mais um produto do acaso que de imposição, pois as ex-colônias não possuíam os recursos necessários para produzir os bens importados e seus setores sociais dominantes tinham grande interesse na continuidade da exportação. De fato, os "produtores" de bens primários podiam absorver pelo menos parte do quantum que antes lhes era tirado através do antigo padrão de exploração colonial, e suas "economias coloniais" recebiam o primeiro impulso para a internalização de um mercado capitalista moderno. Entretanto, a dominação externa era uma realidade concreta e permanente, a despeito do seu caráter como processo puramente econômico. Os efeitos estruturais e históricos dessa dominação foram agravados pelo fato de que os novos controles desempenhavam uma função reconhecida: a manutenção do status quo ante da economia, com o apoio e a cumplicidade das "classes exportadoras" (os produtores rurais) e os seus agentes ou os comerciantes urbanos. O esforço necessário para alterar toda a infraestrutura da economia parecia tão difícil e caro que esses setores sociais e suas elites no poder preferiam escolher um papel econômico secundário e dependente, aceitando como vantajosa a perpetuação das estruturas econômicas construídas sob o antigo sistema colonial.

O terceiro tipo de dominação externa apareceu como consequência da reorganização da economia mundial, provocada pela revolução industrial na Europa. Na verdade, o neocolonialismo citado acima teve uma função importante na dinamização da revolução industrial. Ele foi uma fonte (através do "comércio triangular") de acumulação de capital nos países europeus, especialmente na Inglaterra, e originou diversos mercados nacionais em crescimento postos sob-reserva, vitais para o desenvolvimento do capitalismo industrial ${ }^{2}$. Entretanto, a transformação do capitalismo na Europa provocou novas formas de articulação das economias periféricas da América Latina, na direção dos dinamismos das economias capitalistas centrais. As novas tendências emergiram gradualmente, todavia a mudanças nos padrões existentes de dominação externa tornaram-se evidentes após a quarta ou quinta década do século XIX e converteram-se numa realidade inexorável nas últimas quatro décadas daquele século. As influências externas atingiram todas as esferas da economia, da sociedade e da cultura, não apenas através de mecanismos indiretos do mercado 
mundial, mas também através de incorporação maciça e direta de algumas fases dos processos básicos de crescimento econômico e de desenvolvimento sociocultural.

Assim, a dominação externa tomou-se imperialista, e o capitalismo dependente surgiu como uma realidade histórica na América Latina4.

Esse processo às vezes é descrito de forma idílica. Alguns contrastes entre o período de predominância europeia, até a Grande Depressão (1929), e a situação atual são tão impressionantes que as condições anteriores de financiamento e de controle externo têm sido encaradas como favoráveis aos países da América Latina. Contudo, a chamada "idade de ouro do capital. estrangeiro"5 foi uma idade de ouro apenas para os países europeus e, até certo ponto, para os Estados Unidos. A Inglaterra, por exemplo, convertia todas as possíveis mudanças econômicas, sociais e culturais em puros negócios - as atividades dos Estados nacionais na construção de uma infraestrutura econômica, a especulação imobiliária em áreas rurais e urbanas, a diferenciação ou a expansão dos sistemas de comércio, de produção, de transporte, de trabalho, de saúde, de educação etc. O controle financeiro das emergentes economias satélites tornou-se tão complexo e profundo que o esquema exportação - importação foi refundido para incluir a "integração" do comércio interno, a "proteção" dos interesses rurais ou da modernização da produção rural, a "introdução" das indústrias de bens de consumo, a "intensificação" das operações bancárias etc. Em síntese, as economias dependentes foram transformadas em mercadoria, negociáveis à distância, sob condições seguras e ultralucrativas.

O lado negativo desse padrão de dominação imperialista aparece claramente em dois níveis diferentes. Primeiro, no condicionamento e reforço externos das estruturas econômicas arcaicas, necessárias à preservação do esquema da exportação - importação, baseado na produção de matérias-primas e de bens primários. Segundo, no malogro do "modelo" de desenvolvimento absorvido pela burguesia emergente das nações europeias hegemônicas. Na realidade, a revolução burguesa não foi acelerada, mesmo nos países mais avançados da América Latina, através de um impulso econômico deliberado procedente da Europa. Tanto para o "moderno" como para o "antigo" colonialismo (em termos dos dois padrões de dominação imperialista), a integração nacional das economias dependentes sempre foi negligenciada. Os objetivos manifestos e latentes foram dirigidos para os ganhos líquidos, isto é, para a transferência do excedente econômico das economias satélites para os países hegemônicos. Sob esse aspecto, a "idade de ouro" do imperialismo europeu encerrou o circuito iniciado pelo antigo colonialismo e expandido pelo neocolonialisrno, ambos de origem europeia, formando o burguês complacente, o equivalente histórico latino-americano do "bourgeois conquerant".

O quarto tipos de dominação externa surgiu recentemente, em conjunção com a expansão das grandes empresas corporativas nos países latino-americanos - muitas nas esferas comerciais, de serviços e financeiras, mas a maioria nos campos da indústria leve e pesada. Essas empresas trouxeram à região um novo estilo de organização, de produção e de marketing, com novos padrões de planejamento, propaganda de massa, concorrência e controle interno das economias dependentes pelos interesses externos. Elas representam o capitalismo corporativo ou monopolista, e se apoderaram das posições de liderança - através 
de mecanismos financeiros, por associação com sócios locais, por corrupção, pressão ou outros meios ocupadas anteriormente pelas empresas nativas e por seus "policy-makers".

Três pontos são muito importantes, mesmo numa exposição sintética. Primeiro, essa tendência envolve um controle externo simétrico ao do antigo sistema colonial, nas condições de um moderno mercado capitalista, da tecnologia avançada, e da dominação externa compartilhada por diferentes nações: os Estados Unidos, como superpotência, e outros países europeus e o Japão, como parceiros menores, mas dotados de poder hegemônico. No fundo, tal tendência implica um imperialismo total, em contraste com o imperialismo restrito, descrito acima. O traço específico do imperialismo total consiste no fato de que ele organiza a dominação externa a partir de dentro e em todos os níveis da ordem social, desde o controle da natalidade, a comunicação de massa e o consumo de massa, até a educação, a transplantação maciça de tecnologia ou de instituições sociais, a modernização da infra e da superestrutura, os expedientes financeiros ou do capital, o eixo vital da política nacional etc. Segundo, esse tipo de imperialismo demonstra que mesmo os mais avançados países latino-americanos ressentem-se da falta dos requisitos básicos para o rápido crescimento econômico, cultural e social em bases autônomas. Como nos outros três períodos, a implementação de mudanças é feita por pessoal estrangeiro, transplantação maciça de tecnologia e de instituições, suprimento externo de capital e de controle financeiro. Terceiro, ela prova que uma economia satélite ou dependente não possui as condições estruturais e dinâmicas para sobrepujar nacionalmente, pelos esforços de sua burguesia (isto é, lato sensu, os setores dominantes das classes alta e média), o subdesenvolvimento e suas consequências. Como ocorre com os interesses privados externos, os interesses privados internos estão empenhados na exploração do subdesenvolvimento em termos de orientações de valor extremamente egoístas e particularistas. Quando o assim chamado estágio de "decolagem" parecia aproximar-se, a expansão iniciava-se como um processo impulsionado pelos interesses mais poderosos e, portanto, controlado a partir de fora. A ilusão de uma revolução industrial liderada pela burguesia nacional foi destruída, conjuntamente com os papéis econômicos, culturais e políticos estratégicos das elites no poder latino-americanas. Agora, uma nova imagem do capitalismo (um neocapitalismo?), da "burguesia nacional" e da "interdependência internacional" das economias capitalistas está sendo reconstruída. para justificar a transição atual e para criar a nova espécie de ideologia e de utopia burguesas dependentes. Os quatro tipos de dominação externa foram caracterizados como uma projeção de seu "background" histórico e de sua sequência sociocultural. Nessa perspectiva, apenas alguns países, como Argentina, Uruguai, Brasil, México, Chile etc., conheceram sucessivamente todas as formas de dominação externa. Outros países, como Haiti, Bolívia, Hunduras, Nicarágua, Guatemala, El Salvador, República Dominicana, Paraguai, Peru etc., experimentaram a primeira e a segunda formas típicas de dominação externa, tornando-se economias de enclave e versões modernizadas do antigo sistema colonial ou do neocolonialismo transitório do início do século XIX ${ }^{6}$. Por outro lado, os países que atingiram condições para absorver os dois tipos diferentes de dominação imperialista somente atingiram as situações descritas graças a um considerável crescimento econômico interno e à existência de estruturas de poder nacionais eficientes, ambos utilizados pelas burguesias desses países para criar uma posição de barganba na economia mundial e na organização internacional de poder. 
A incorporação ao mercado mundial e às estruturas internacionais de poder numa posição heteronômica envolve uma forma peculiar de integração nacional. Nenhum país possui uma economia homogênea e potencialidades organizadas de desenvolvimento auto-sustentado efetivo. A dominação externa, em todas as suas formas, produz uma especialização geral das nações como fontes de excedente econômico e de acumulação de capital para as nações capitalistas avançadas. Assim, as diferentes transições da economia colonial para a economia nacional ou da escravidão e do capitalismo comercial para o capitalismo industrial sempre produzem três realidades estruturais diversas. Primeiro, a concentração de renda, do prestígio social e do poder nos estratos e nas unidades ecológicas ou sociais que possuem importância estratégica para o núcleo hegemônico de dominação externa. Segundo, a coexistência de estruturas econômicas, socioculturais, e políticas em diferentes "épocas históricas", mas interdependentes e igualmente necessárias para a articulação e a expansão de toda a economia, como uma base para a exploração externa e para a concentração interna da renda, do prestígio social e do poder (o que implica a existência permanente de uma exploração pré ou extracapitalista, descrita por alguns autores como "colonialismo interno") $)^{7}$. Terceiro, a exclusão de uma ampla parcela da população nacional da ordem econômica, social e política existente, como um requisito estrutural e dinâmico da estabilidade e do crescimento de todo o sistema (essa exclusão variava, em 1964, de um quarto até a metade ou três quartos da população, conforme os países) $)^{8}$ O desafio latino-americano, portanto, não é tanto como produzir riqueza, mas como retê-la e distribuí-la, para criar pelo menos uma verdadeira economia capitalista moderna.

\section{O novo imperialismo e a hegemonia dos Estados Unidos}

A nova forma de imperialismo não é apenas um produto de fatores econômicos. No centro do processo está a grande empresa corporativa e, portanto, o capitalismo monopolista. Por isso, as mudanças da organização, das funções e do poder financeiro das empresas capitalistas foram produzidas por mudanças nos padrões de consumo e de propaganda de massa, na estrutura de renda, por uma revolução concomitante na tecnologia e nos padrões burocráticos de administração, e pelos efeitos múltiplos e cumulativos da concentração financeira do capital na internacionalização do mercado capitalista mundial. Esses são processos históricos, de natureza socioeconômica e sociocultural. Mas a influência dinâmica decisiva foi política. A existência de uma economia socialista bem sucedida e expansiva, dotada pelo menos de padrões equivalentes de tecnologia, organização burocrática, produtividade, crescimento acelerado e internacionalização, compeliu as nações capitalistas avançadas da Europa, América e Ásia para uma defesa agressiva do capitalismo privado, especialmente após a II Guerra Mundial. Assim, enquanto o antigo imperialismo constituía uma manifestação da concorrência nacional entre economias capitalistas avançadas, o imperialismo moderno representa uma luta violenta pela sobrevivência e pela supremacia do capitalismo em si mesmo. Nesse clima político, a expansão incoercível da empresa corporativa, a hiperinfluência das finanças internacionais e a hegemonia dos Estados Unidos foram recebidas como um preço razoável, pelas burguesias nacionais dos países capitalistas avançados, inclusive a Inglaterra, França, Alemanha e Japão. 
Alguma tensões e rupturas permaneceram, mas são manipuladas em condições seguras para a defesa e o fortalecimento dos 'interesses privados', isto é, do capitalismo.

O novo padrão de imperialismo é, em si mesmo, destrutivo para o desenvolvimento dos países latino-americanos. A razão é facilmente compreensível. Não possuindo condições para um crescimento autossustentado, para a integração nacional da economia e para um rápida industrialização ${ }^{9}$, os países capitalistas da América Latina estavam tentando explorar uma espécie de miniatura do modelo europeu de revolução burguesa, através de expedientes improvisados e oportunistas. Enquanto o fluxo de capital externo e de controle financeiro chegava através da concorrência multinacional regulada pelo mercado mundial, algumas medidas protecionistas diretas ou indiretas podiam ser tomadas e reforçadas. Por outro lado, durante os períodos em que as influências capitalistas externas decresceram, os países da região encontraram oportunidades para a expansão interna, de acordo com aquele modelo (isso aconteceu em conexão com a I Guerra Mundial, a Grande Depressão, ou a II Guerra Mundial).

O melhor estratagema sempre consistiu na absorção de meios para a produção de produtos importados e na seleção estratégica de importação de bens e serviços ${ }^{10}$. Finalmente, em alguns países, o Estado foi capaz de construir e desenvolver indústrias básicas, através de empresas públicas ou semipúblicas como uma base para a diferenciação da produção industrial, a aceleração autônoma do crescimento econômico e a integração nacional da economia.

A erupção do moderno imperialismo iniciou-se suavemente, através de empresas corporativas norte-americanas ou europeias, que pareciam corresponder aos padrões ou às aspirações de crescimento nacional auto-sustentado, conscientemente almejado pelas burguesias latino-americanas e suas elites no poder ou pelos governos. Por isso, elas foram saudadas como uma contribuição efetiva para o "desarrolismo" ou o "desenvolvimentismo", recebendo um apoio econômico e político irracional. Assim que elas se tomaram um pólo econômico ativo das economias latino-americanas, revelaram sua natureza, como uma influência estrutural e dinâmica interna e como um processo histórico-econômico. As empresas anteriores, moldadas para um mercado competitivo restrito, foram absorvidas ou destruídas ${ }^{11}$, as estruturas econômicas existentes foram adaptadas às dimensões e às funções das empresas corporativas, as bases para o crescimento econômico autônomo e a integração nacional da economia, conquistadas tão arduamente, foram postas a serviço dessas empresas e dos seus poderosos interesses privados.

O processo corno um todo não é um fenômeno norte-americano. No entanto, os Estados Unidos desempenharam o papel pioneiro e dominante ${ }^{12}$. Outras nações, especialmente europeias (como a Alemanha, a França, a Inglaterra etc.) e o Japão tomaram parte nesse processo lucrativo de recolonialismo. Mas a 'influência dos Estados Unidos é um caso à parte, devido ao caráter e às consequências de sua expansão econômica na América Latina ${ }^{13}$.

A hegemonia dos Estados Unidos pode ser contrabalanceada nas nações capitalistas avançadas. Essas nações possuem recursos materiais e humanos para resistir às implicações negativas da empresa corporativa norte-americana, e para limitar e mesmo para estabelecer controles seletivos das consequências culturais ou políticas resultantes da supremacia econômica dos Estados Unidos. Os países latino-americanos carecem desses recursos materiais e humanos. Por outro lado, suas burguesias nacionais e suas elites no 
poder não estão submetidas a controle público e a pressões democráticas. Em consequência, o processo de modernização, iniciado sob a influência e o controle dos Estados Unidos, aparece como uma rendição total e incondicional, propagando-se por todos os níveis da economia, da segurança e da política nacionais, da educação e da cultura, da comunicação em massa e da opinião pública, e das aspirações ideais com relação ao futuro e ao estilo de vida desejável. Apenas alguns setores, movidos por sentimentos políticos, intelectuais ou religiosos, opuseram-se a essa forma de recolonialismo. O "sistema", isto é, as elites, econômicas, políticas e culturais são a favor dele, como a única alternativa para enfrentar a "subversão", para lutar contra a "corrupção", e para "evitar" o comunismo...

O que torna a hegemonia dos Estados Unidos entre as nações latino-americanos uma força incontrolável e perigosa é a presente concepção norte-americana de segurança, fronteira econômica e ação conjunta contra mudanças radicais ou revolucionárias nos países vizinhos. Essa concepção implica, na prática, a incorporação desses países ao espaço econômico e sociocultural dos Estados Unidos, por meios organizados institucionalmente. A maioria dos cientistas sociais está preocupada com a deterioração dos termos de troca ${ }^{14}$ ou com os padrões ultra-expoliativos inerentes às modernas tendências de dominação econômica externa ${ }^{1514}$. Todavia, os aspectos econômicos são apenas uma face de uma amarga realidade. Diversas instituições estão executando diferentes funções ligadas à incorporação dos países latinoamericanos ao espaço econômico e sociocultural dos Estados Unidos. A empresa corporativa é a mais visível dessas instituições; mas as menos visíveis são talvez ainda mais prejudiciais. Elas abrangem instituições oficiais, semioficiais ou privadas, encarregadas de conduzir a política de controle global das finanças, da educação, da pesquisa científica, da inovação tecnológica, dos meios de comunicação em massa, do emprego extranacional das políticas, das forças armadas e mesmo dos governos.

$\mathrm{Na}$ verdade, as economias, as sociedades e as culturas latino-americanas estão sendo reconstruídas de acordo com interesses e valores políticos que adquirem uma natureza pervertida nas condições locais. Poderíamos discutir se seria desejável o consumo em massa, o desperdício de riqueza imposto por uma economia de consumo de massa, o tipo de homem comum produzido por uma sociedade de meios de comunicação de massa, de organização social que rotiniza a competição neurótica, a frustração e a agressão etc. A sociedade norte-americana possui, sem dúvida, capacidade para conciliar tais coisas como o seu "background" histórico.

Por outro lado, a estrutura da renda, a distribuição do prestígio social e a eficiência de alguns direitos humanos básicos, nos Estados Unidos, fornecem um mínimo de proteção às minorias destituídas. O recurso ao conflito é frequentemente necessário e permitido, pelo menos dentro de certos limites. Nos países latino-americanos, entretanto, não possuímos uma democracia real. A situação é bem conhecida nos Estados Unidos, especialmente nos círculos empresariais e no seio das agências oficiais, semioficiais e privadas que operam na região, e pelo governo. Todavia, a deterioração das estruturas políticas é aceita e aprovada da mesma maneira que a deterioração dos termos de troca, porque ambas as tendências são entendidas como um "custo natural" da hegemonia e da segurança dos Estados Unidos. O mesmo ocorre com os programas especiais de controle de natalidade, inovação tecnológica, educação etc., projetados e aplicados sem consideração (ou com pouca consideração) pelas necessidades e potencialidades concretas 
dos países receptores. O que está em jogo são os requisitos políticos de uma incorporação dependente mas eficaz desses países ao espaço econômico e sociocultural dos Estados Unidos.

Raciocinando em termos dos problemas de seu país, um brilhante escritor norte-americano perguntou: o que aconteceu com a "nossa revolução"?16 A mesma questão poderia ser colocada no exterior, quando se consideram os problemas criados para a América Latina pelos padrões de dominação dos Estados Unidos. Os campeões da liberdade e da democracia agora estão apoiando todo tipo de iniquidades, para assegurar os interesses privados de suas empresas corporativas ou o que supõem ser a segurança de sua nação. A autoimagem usual, que os cidadãos dos Estados Unidos cultivam com orgulho, não se ajusta a esse quadro. Não há, simplesmente, compatibilidade entre a "crença na democracia" e o "respeito pelos direitos humanos básicos", e os fins ou consequências da política hegemônica (ou a ausência de uma política?) dos Estados Unidos na América Latina. Essa política (ou ausência de política) está introduzindo, de forma crescente, mudanças tecnológicas inúteis, contribuindo para o crescimento da pobreza, e intensificando a expropriação ou a devastação de recursos econômicos escassos. Essa política (ou ausência de política) também está ajudando a revitalização, sob condições modernas, de estruturas de poder ou de privilégios arcaicos e antissociais, pois somente as ditaduras militares ou os regimes autoritários dissimulados conseguem assegurar os alvos visados, de incorporação dos países latino-americanos ao espaço econômico e sociocultural dos Estados Unidos.

De um ponto de vista sociológico, é ilusório supor-se que, por esses meios, uma superpotência hegemônica pode garantir segurança dentro dos limites supranacionais de suas «fronteiras políticas". A segurança real entre nações implica entendimento mútuo, fins comuns, consenso e solidariedade, não apenas ao nível das elites no poder e através dos governos, mas também entre seus povos. Poderia dizer-se que, em nossos dias, uma superpotência hegemônica pode negligenciar esses aspectos como "futilidades morais". Isso é verdade. Mesmo assim, a alternativa é a realpolitik, isto é, uma posição de força que exclui, por si mesma, qualquer tipo de segurança efetiva.

\section{O dilema latino-americano}

Os países latino-americanos enfrentam duas realidades ásperas: 1) estruturas econômicas, socioculturais e políticas internas que podem absorver as transformações do capitalismo, mas que inibem a integração nacional e o desenvolvimento autônomo; 2) dominação externa que estimula a modernização e o crescimento, nos estágios mais avançados do capitalismo, mas que impede a revolução nacional e uma autonomia real. Os dois aspectos são faces opostas da mesma moeda. A situação heteronômica é redefinida pela ação recíproca de fatores estruturais e dinâmicos, internos e externos. Os setores sociais que possuem o controle das sociedades latino-americanas são tão interessados e responsáveis por essa situação quanto os grupos externos, que dela tiram proveito. Dependência e subdesenvolvimento são um bom negócio para os dois lados. Entretanto, sob as condições históricas atuais, o novo padrão de imperialismo e a hegemonia dos Estados Unidos colocam uma questão dramática: podem os países latino-americanos atingir realmente a integração nacional e a autonomia econômica, sociocultural e política através do capitalismo? 
As estimativas demográficas para a região, em 1970, indicam uma população de quase 283 milhões ${ }^{17}$. Todavia, uma grande parte dessa população pode ser considerada como condenada pelo sistema, pois carece dos meios para vender seu trabalho como mercadoria, ou só pode fazê-lo de maneira muito precária. O quadro seguinte, elaborado pela Comissão Econômica para a América Latina (ONU), baseada em estimativas para 1965, descreve a distribuição da renda por grupos: ${ }^{18}$

\begin{tabular}{|l|l|l|l|}
\hline Grupo de Renda & $\begin{array}{l}\text { Porcentagem de } \\
\text { Participação na Renda Total }\end{array}$ & $\begin{array}{l}\text { Renda Média (média } \\
\text { regional = 100) }\end{array}$ & $\begin{array}{l}\text { Renda Média "per capita" } \\
\text { (em dólares)* (ano 1960) }\end{array}$ \\
\hline Os 20\% mais pobre & 3,5 & 18 & 68 \\
\hline Os 30\% abaixo da mediana & 10,5 & 35 & 133 \\
\hline Os 30\% acima da mediana & 25,4 & 85 & 322 \\
\hline Os 15\% acima da mediana & 29,1 & 194 & 740 \\
\hline $5 \%$ do tope & 31,5 & 629 & 2.400 \\
\hline
\end{tabular}

Fonte: Comissão Econômica para a América Latina (ONU) - 1965

Em média, os 50\% mais pobres participam de 14\% da renda total (isto é, recebem cerca de 55 cents por dia!). Esta é a terrível herança de quatro séculos de "tradição colonial' aberta ou dissimulada, a qual não pode ser superada mediante uma forma mais complexa e asfixiante de neocolonialismo. No outro extremo, os $20 \%$ que constituem o grupo de renda superior participam de quase $61 \%$ da renda total, recebendo uma renda por capita média seis vezes maior que a dos outros $80 \%$. Só os $5 \%$ do tope participam de um terço da renda total, o que representa uma renda per capita média doze vezes maior que a dos 50\% de baixa renda. Esse grupo de 20\% compreende um setor muito bem "desenvolvido" e, em termos estritos, a "sociedade cívica" ativa.

É claro que a situação descrita varia relativamente de um país para outro e mesmo com respeito a regiões de um mesmo país ${ }^{19}$. Todavia o spectrum possui um significado sociológico específico, pelo menos para a presente discussão. Ele fornece um sistema de referência empírico para a nossa pergunta. O desafio latino-americano ao capitalismo emerge desse quadro: pode o capitalismo privado, sob condições de extrema concentração interna da renda (e, em consequência, do prestígio social e do poder) e sob condições de dominação externa e de drenagem de riquezas permanentes, enfrentar realmente e mudar uma tal realidade? A lógica da situação tem mostrado que um desafio tão complexo não pode ser enfrentado e modificado através do capitalismo privado, especialmente através desse tipo de capitalismo dependente, que envolve, estrutural e dinamicamente, tanto uma extrema concentração interna da renda quanto uma dominação externa e uma drenagem de recursos permanentes. Em teoria, seria possível presumir que uma mudança radical, da força externa poderia resolver o problema. Uma transferência maciça de capital, de tecnologia e de pessoal qualificado poderia iniciar um novo processo de reorganização econômica, sociocultural e política. Na prática, as coisas não são tão simples. Um processo como esse tem um preço, que os países da América Latina não podem pagar. Por outro lado, para que ele fosse bem sucedido, seriam necessários certos requisitos estruturais e dinâmicos que não existem e não podem ser criados tão facilmente (se existissem, ou pudessem ser criados rapidamente, os países em questão poderiam resolver os problemas por si mesmos). 
A questão real, porém, é diferente. Pelo menos até o momento, o novo modelo de imperialismo limitou a amplitude dentro da qual a iniciativa privada poderia desempenhar funções construtivas e inovadoras. Uma superpotência capitalista necessita de tipos diferentes de mercados externos, desde as economias capitalistas avançadas até economias dependentes, semicoloniais e coloniais. A preservação de sua posição depende de vigilância e controle contínuos da expansão das grandes empresas corporativas, e da intensificação crescente das relações econômicas com os mercados externos. Assim uma superpotência capitalista não pode enfrentar e resolver nem os problemas de seus parceiros menores, nem muito menos os problemas das economias dependentes, semicoloniais e coloniais, incorporadas ao seu espaço econômico, sociocultural e político. Isso explica o fracasso da Aliança para o Progresso na América Latina. Ao mesmo tempo, isso explica também, em nível mais complexo, os padrões de fluxo de capital, nas duas direções ("inflow" e “outflow”), entre os Estados Unidos e as economias latino-americanas. Numa reunião de ministros, promovida pela Comissão Executiva de Coordenação Latino-Americana (Viña del Mar, 15/5/1967), foi reconhecido oficialmente que, apesar dos programas da Aliança, o investimento privado na América Latina, em 1967, produziu um lucro líquido de 1.194 milhões de dólares. Desse total, foram reinvestidos 172 milhões de dólares, aos quais foram adicionados 191 milhões de dólares de investimentos privados $^{20}$. Os países latino-americanos sofreram uma perda da ordem de 831 milhões de dólares ${ }^{21}$. Contudo, isso é parte de um processo global, que afeta todas as economias estrangeiras, relacionadas ou dominadas pela superpotência capitalista, como é revelado pelos seguintes dados: 22

\section{Investimentos diretos e lucros norte-americanos}

\begin{tabular}{lllll} 
& Saída de Capital & & \multicolumn{2}{c}{ Entrada de Capital } \\
& 1965 & 1968 & 1965 & 1968 \\
Mundo (em bilhões de US & 3,5 & 2,9 & 4,9 & 5,8 \\
\hline Europa Ocidental & $42,9 \%$ & $34,4 \%$ & $22,4 \%$ & $22,4 \%$ \\
Só o Reino Unido & $8,6 \%$ & $3,4 \%$ & $8,2 \%$ & $6,9 \%$ \\
Canadá & $27,6 \%$ & $13,8 \%$ & $18,4 \%$ & $17,2 \%$ \\
America Latina & $8,6 \%$ & $10,3 \%$ & $24,5 \%$ & $25,9 \%$ \\
Oriente Médio etc. & $20,9 \%$ & $41,5 \%$ & $34,7 \%$ & $34,5 \%$ \\
\hline
\end{tabular}

As economias capitalistas mais avançadas possuem mecanismos de autodefesa. Todavia, também estão sob pressão e necessitando mercados externos (inclusive o mercado dos Estados Unidos), em particular, precisam dos mercados dependentes, semicoloniais e coloniais (dos quais é possível maior drenagem de riquezas). $\mathrm{Na}$ realidade, a posição hegemônica dos países de segunda ordem está permanentemente ameaçada pela supremacia tecnológica, financeira e política dos Estados Unidos, que impõem uma política econômica realisticamente orientada para a sua autoproteção. Em consequência, o novo modelo de imperialismo envolve um crescimento rápido do fluxo internacional do capital. Porém, a rigidez do controle externo e da exploração também aumenta, como um produto estrutural da situação global. 
Portanto, o uso da militarização do poder ou do autoritarismo civil como estratagema político para auxiliar "um desenvolvimento mais rápido e seguro" na América Latina, nessas condições, é absurdo. O colunista de uma revista brasileira escreveu que 'os modelos autoritários, aplicados no mundo em desenvolvimento, correspondem - com mais ou menos autenticidade - à necessidade urgente de intensa acumulação de capital em países nos quais a expansão do mercado interno, por si só, não é capaz de assegurar a taxa necessária de acumulação”. ${ }^{23}$ O que falta, nessa descrição, é uma análise explícita do processo de acumulação de capital no contexto dos países dependentes e subdesenvolvidos. Nesse contexto, o novo tipo de imperialismo e de hegemonia norte-americana transfere para o exterior a estimulação, a orientação e o controle desse processo. O fardo da acumulação de capital é carregado pelos países latinoamericanos, mas seus efeitos multiplicadores mais importantes são absorvidos pelas economias centrais, que funcionam como centros dinâmicos de apropriação das maiores quotas do excedente econômico gerado.

Os setores sociais dominantes e as elites no poder dos países latino-americanos, assim como a superpotência capitalista externa e as nações hegemônicas associadas, defendem a esperança de que é possível 'reproduzir a história'. Há uma convicção especialmente forte segundo a qual o novo padrão de dominação imperialista pode ser adaptado ao 'desenvolvimento com segurança', para ambas as partes. Entretanto, apesar da rigidez econômica, cultural e política, externa e interna, é discutível que o imperialismo moderno possa ter um êxito equivalente ao do antigo imperialismo. As tensões provocadas pelas migrações internas, a pobreza generalizada e a frustração sistemática não podem ser suprimidas sem mudanças estruturais substancias. E, atualmente, o capitalismo privado não é um caminho privilegiado e exclusivo. Ele enfrenta soluções alternativas, do capitalismo de Estado ao socialismo.

A maioria silenciosa dos pobres não pode ser banida eternamente da história. O mesmo é verdadeiro com referência ao protesto organizado e ao radicalismo político, desde os movimentos da classe inferior, até as confrontações estudantis de classe média, intelectuais ou religiosas, e o inconformismo moral dos setores esclarecidos das classes média e superior. A consciência da situação atual e a inconformidade diante dela, aberta ou latente, são dois fenômenos gerais e interdependentes. Por outro lado, a modernização tecnológica, a entrada gradual de capital e o crescimento dos mercados internos podem ser considerados fatores importantes de mudança - em atitudes e orientações de valor, como em relações de classe e usos sociais da competição e do conflito. O que hoje é um processo econômico controlado do exterior e do interior pelos interesses privados, pode transformar-se rapidamente num processo político incontrolável. Essa sempre tem sido a lição da história, nas transformações que levaram do colonialismo ao capitalismo e ao socialismo. Os dois períodos de imperialismo foram e são valiosos para a emergência de uma consciência social crítica, do radicalismo político e da revolução social, dentro da ordem ou contra ela.

Desse ponto de vista, o dilema latino-americano não nasce da incongruência entre o sistema compartilhado de valores ideais e a práxis social (como foi descrito, com referência aos Estados Unidos, por Myrdal e Hollingshead). Ele provém da mais profunda necessidade histórica e social de autonomia e equidade. Isso significa que as alternativas políticas efetivas deixam uma margem estreita para as opções coletivas. Se os setores sociais dominantes e as elites no poder realmente desejam um desenvolvimento gradual e seguro, e se forem capazes de obter apoio popular, suas probabilidades de êxito dependem de um 
forte nacionalismo revolucionário. Sob as condições econômicas, socioculturais e políticas dos países latinoamericanos essa alternativa implica a implantação e aperfeiçoamento de um novo tipo de capitalismo de Estado, capaz de ajustar a velocidade e a intensidade do desenvolvimento econômico e da mudança sociocultural aos requisitos da "revolução dentro da ordem social'. A outra resposta alternativa só pode surgir de uma rebelião popular e radical, de orientação socialista. A estranha combinação de uma ampla maioria de gente destituída, miserável ou quase-miserável, a uma exploração externa implacável e uma péssima utilização interna da riqueza, por minorias privilegiadas, gera um componente histórico imprevisível. A explosão social não é planejada com antecipação. Como em Cuba, ela pode sobrevir inesperada e dramaticamente.

A estrutura da sociedade e suas permanentes condições de anemia contêm os ingredientes básicos da desintegração: quando as forças da rebelião são liberadas, a ordem social não pode funcionar como um fator de autopreservação e de auto regeneração, porque ela não é desejada sequer pelos que tiram proveito das desigualdades e iniquidades existentes. A última alternativa, sem dúvida, abre caminho para a realização dos padrões mais elevados da razão humana e para a liberação real das sociedades latino-americanas. Todavia, ambas as soluções poderiam dar início a novas vias de evolução da América Latina, na direção de uma história de povos livres e independentes.

\section{Notas:}

${ }^{1}$ Tradução revista pelo autor. Texto da conferência lido no auditório da Universidade de Toronto (10/3/1970). Publicação prévia: F. Fernandes, The Latin Amerlcan in Residenc e Lectur es, Toro ntc. l"niversity af Toronto, 1969-1970, ps. 3-23. FERNANDES, Florestan. Padrões de Dominações. In: FERNANDES, Florestan. Capitalismo Dependente e Classes Sociais na América Latina. RJ: Zahar Editores, 1975.

2 "Considerado fundador da sociologia crítica no Brasil, Florestan Fernandes foi o mestre de uma geração de cientistas sociais. Tentando conciliar a contribuição teórica de Karl Marx, Max Weber e dos funcionalistas, sua obra expressa uma interpretação original - sob muitos aspectos controvertida - de nossa sociedade. Na universidade brasileira, foi o pioneiro no estudo das questões raciais; da escravidão e da abolição; das transformações de classe que esses processos históricos significaram; da revolução burguesa no Brasil; dos processos revolucionários na América Latina.

Professor na Universidade de São Paulo desde 1945, catedrático em 1964 (com uma tese importante sobre a transição do trabalho escravo para o trabalho livre, "A integração do negro nas sociedades de classe"), Florestan Fernandes foi cassado, pelo AI-5, em 1969. Ensinou, então, em universidades canadenses e norte-americanas. Em 1978 passou a lecionar na PUC-SP, mas somente em 1986 voltou à USP.

Eleito deputado federal à Constituinte, em 1986, pelo Partido dos Trabalhadores, foi reeleito em 1990. Algumas de suas obras: A organização social dos Tupinambá (1949), Negros e brancos em São Paulo (1959), A sociologia numa era da revolução social (1962), A integração do negro na sociedade de classes (1964), Sociedade de classes e subdesenvolvimento (1968), Capitalismo dependente e classes sociais na América Latina (1973), A revolução burguesa no Brasil (1975), A Universidade Brasileira: reforma ou revolução? (1975), A sociologia no Brasil (1977), A condição do sociólogo (1978), Da guerrilha ao socialismo: a Revolução Cubana (1979), A natureza sociológica da sociologia (1980), O que é revolução? (1981), A ditadura em questão (1982), Nova República (1986). Por: José Carlos Ruy (fonte: Revista Princípiosn ${ }^{\circ}$ 35). Disponível em: https://www.marxists.org/portugues/fernandes/index.htm Acesso em: 02.09.2019 23:17.

3 Sobre esse assunto e pata bibliografia básica, ver esp. F. Fernandes, Sociedade de Classes e Subdesenvolvimento, Rio de Janeiro, Zahar Editores, 1968, cap. 11, ps, 21.103, 204-256, e T. Halperin Donghi, Hist6ria Contemporânea da América Latina, Madri, Alianza Editorial, 1969. As seguintes contribuições recentes merecem atenção especial: A. G. Frank, Capitalism and Underdeuelopment in Latin .Amerlca, Nova York, Monthly Review Press, 1967; J. Graciarena, Poder y Clases Sociales en el Desarrollo de América Latina, Buenos Aires, Editorial Paidós, 1967; C. Furtado, Deueloprnent and Stagna .. tion in Latin América, New Haven, Vale University Press, 1965; F. H. Cardoso e E. Faletto, Depen dencia y Desarrollo en América Latina, México, Sigla Veintiuno Editores SA., 1969; R. Vekernans, Ismael Fuenzalida e outros, M arginalidad en América Latina, Santiago deI Chile, nasxt-Editorial Herder, 1969 (cap. 1); A. Garcia, La Estrutura del Atraso en América Latina, Buenos Aires, Editorial Pleamar, 1969; R. N. Adams, Th e Second Sotoing, San Francisco, Cal., Chandler Publishing COI J 1967. 
${ }^{4}$ Sobre as diferentes tendências da influência econômica européia na América Latina, cf. esp.: Economic Comission for Latin América, Externai Financing in Latin Amerlca, Nova York, United Nations, 1\%5 (parte I); Raymon Bertran e outros, La Participación de Europa en el Financiamento del Desarrollo de América Latina, Banco Interamericano de Desarrollo, s, d.

5 O período de 1874-1914 (ver CEPAL, op, cit., ps, 7-14). Os Estados Unidos tornaram-se um parceiro importante da Inglaterra, França e Alemanha só no fim do século XIX.

${ }^{6}$ Cf. J. Lambert, América Latina: Estruturas Sociais e Pollticas, tradução de L. L. de Oliveira, São Paulo, Companhia Editora Nacional, 1969 (cap. 1); e especialmente F. H. Cardoso e E. Faletto, Depetidencia y Desarrollo en América Latina\} op, cit., ps, 43·101.

7 Cf. P. Gonzáles-Casanova "InternaI CoIonialism and National Developrnent" (em I. L. Horowitz, J. de Castro e J. Gerassi (orgs.), Latin Amerlcan Radicalism, op. cit., ps, 118-139.

8 Cf. J. Larnbert, op. cii., ps. 52-53, entrada 10 da tabela.

9 Ver esp.: R. Prebisch, Hacia una Dinámica del Desarrollo Latinoamericano, 11 ar del Plata, Argentina, CEPAL, 1963; C. Furtado. Dé relo p ment and Stognation in Latin América, op. cit.; Forli/ação Econômica da América Latina, Rio de Janeiro, Lia Editor, segunda edição, 19iO: Cornisión Económica para América L.. atina, EI Pro ceso de I ndustrializ ació n em América Latina) Nova York, ::\aciones LTnidas 1965.

${ }^{10}$ Ver esp.: M. C. Tavares, "Auge y Declinación del Proceso de Sustitución de Importaciones en el Brasil", Boletin Econárnico de América Latina, Santiago deI Chile, IX-L, 1964, ps. 1-62; O. Sunkel, Política Nacional de Desarrollo )' Dependencia Externa, Edición rnimeografada, Santiago deI Chile, 1966; Comisi6n Econ6mica para América Latina, El Segundo Decenio de Ias Naciones Unidas para el Desarrollo. El Cambio Social y la Polltica de Desarrollo en América Latina, Santiago del Chile, Naciones Unidas, 1969 (ps. 179 e seguintes).

11 Ver a análise de um caso concreto na Argentina (K. H. Silvert, La Sociedad Problema: Reaccián y' Reuolucián en América Latina, tradução de N. Rosenblatt, Buenos Aires, Editorial Paidós, 1962) sobre o financiamento externo da industrialização: Comisi6n Econômica para América Latiria, El Proceso de Ln dustrialisacián en Arnérica Latina, Pp. cit., ps. 188-227; alguns aspectos da influência dos Estados Unidos são descritos por C. Furtado, Dé uelopment and 15/ngnation $14 \mathrm{Jl}$ o\&4merica Latina) op. cite) e "United States Hegemony and the Futurc of Latin América" (em I. L. Horowitz, J. de Castro e J. Gerassi, op. cit., ps. 61-74); os processos envolvidos são interpretados sociologicamente por F. Fernandes, op. cito) capítulos 1, 3 e 4. Sobre o modelo emergente de dominação externa, sob hegemonia norte-americana, esp. T. dos Santos, EI Nuevo Carácter de la Dependencia, Santiago do Chile, Universidade do Chile, 1968.

12 Ver Economic Commission for Latin América, Externai Financin g in Laiin America, op. cito) Zoe. cit, e caps. II! e X.

13 Ver indicações nas referências 10 e 11, acima; esp. T. dos Santos. El J./UfZ'O Car áct er de la Dependencia) op. cit,

14 Sobre a extensão e as consequências da deterioração dos termos da troca, cf. Instituto Latinoamericano de Planificación Economica e Social, La Brecha Comercial y la Integración Lationoamericana, México, Siglo Veituno Editores, 1967.

15 Ver especialmente A. Gunder Frank, "The Underdevelopment Policy of United States in Latin Americana", Nacla Newsletter, II-8, dezembro de 1969, ps. 1-9.

16 H. P. Miller, Rich Man, Poor Man, Nova York, Signet Books, 1964, esp. ps. 54-70.

${ }_{17}$ Economy Commission for Latin America, The Latin America Economy in 1968J Nova York, United Nations, 196-9, ps, 3-4.

18 CEPAL; The Latin America Economy in 1968) op . cii., p. 5.

19 Sobre as variações entre alguns países latino-americanos, ver Comisión Económica para América Latina, Boletin Económico de América Latina, XII-2, 1967- “ La distribuición del Ingreso em América”, os. 152-175; e El Desarollo Económico y la Distribuición del Ingreso em la Argentina, Nova York, Naciones Unidas, 1968.

${ }^{20}$ Ver O Estado de S. Paulo (São Paulo, Brasil, 15/5/69).

${ }^{21}$ Sobre o assunto, de um modo mais geral, ver A. G. Frank, nota 14.

${ }^{22}$ Cf. Le Monde, Paris (13-19/3/19690; fonte: First National City Bank.

23 Visão, São Paulo (14/2/1970, p. 39). 